$$
\begin{aligned}
& \text { NAL PROPOSAL NO. } 71 \\
& \text { Correspondent: D. Drickey } \\
& \text { Physics Department } \\
& \text { U. of Calif, Los Angeles } \\
& \text { Los Angeles, Calif } 90024 \\
& \text { FTS/Off-net } \\
& 213-688-2000 \\
& 825-4541
\end{aligned}
$$

\title{
A MEASUREMENT OF THE PION RADIUS
}

C. Buchanan, D. Drickey, D. Rudnick, P. Shepard, D. Stork, H. Ticho

$$
\text { UCLA }
$$

A. Wehmann

NAL

$$
\text { June 1, } 1970
$$



C. Buchanan
UCLA
D. Drickey
UCLAA
D. Rudnick
UCLA
P. Shepard
UCLA
D. Stork
UCLA
H. Tícho
UCLA

AND

A. Wehmann

June 1, 1970
Spokesman: D. Drickey

\section{ABSTRACT}

We propose a wire spark chamber experiment to measure the pion electronagnetic radius accurate to $\pm 0.03 f$ by measuring the scattering cross section for $50--80 \mathrm{GeV}$ pions from electrons in a liquid hydrogen target. The data will distinguish between the $\rho$ dominance prediction of $0.64 \mathrm{f}$ and the "proton-1ike" radius to $0.81 \mathrm{f}$. 


\section{PHYSICS JUSTIFICNITON}

The electromgretic dimensions of the various particles are of fundanental interest. The charge radius of both the pion and proton are predicted to be $0.64 \mathrm{f}$ from rho-doninance, yet the proton radius measured fron clectron-proton scattering is 0.81 . A measurement of the pion radius is crucial in ordor to unlorstand whether this differ. ence is due to some peculiarity of the nucleon or to a breakdown of vector doninance. In a larger sense, this is one place where theory has far out-strippod exporinent. The pion radius is one of the fundamental mubors of plysies and has inspired a wide variety of theoretical predictions ony loosoly subjoctod to cxpoxinental test. Many of these predictions fail to differentiate between "proton-1ike" (0.81f) and "ho-doninance" (0.64f) redi. Reont speculation has suggested that the pion radius my be evo smallor if highor wass particles couple to the photon. This experinent wil differentiate anong these values for the radius by moasuring cross sections to a precision of one por cent. This accuracy distinguishes betwoen the two values of $0.64 f$ and $0.81 f$ by six standard deviations and rejects a point-like pion by about fifteon standard deviations.

We vill masure the cross scotion differential in the final state electron energy. This is given in tems of the point cross section by

$$
\frac{d \sigma}{d E}=\left(\frac{d \sigma}{d E}\right)_{p o i n t} f_{\pi}^{2}
$$

where $f_{\pi}$ is the pion fom factor. Since the momentum txansfer is small in 
pine collisions, $f_{\gamma}$ depends only on the mean radius, $\left\langle r_{\pi}\right\rangle$ and, $q^{2}$, the foux monentum-transfer squared:

$$
f_{\pi}=1+\frac{1}{6} q^{2}<x_{\eta}>2
$$

Direct pi-e scattering has been measured in several experiments. The nost accurate completed experinent ${ }^{2}$ quotes $<r_{\pi}><3 \times 10^{-13} \mathrm{~cm}$. A Dubna grow led by E. Tsysanov is scheduled to carry out an cxperiment whose ain is to moasure the radius with a $50 \mathrm{GeV} / \mathrm{c} \pi^{-}$beam and a wire-sparkchanber spectroncter. Even if the Serpukhov experinent is successful, the added intensity and inproved techniques of this proposed experiment vill provide a more accurate result with less systematic error. A group fron Haxvard led by Richred Hilson has proposed to do the experiment at the AGS with a pion bean of about $25 \mathrm{GeV} / \mathrm{c}$. The effoct to be neasured in the present experiment is at least a factor of three larger. Table I compares the effect expected in the cross section for three incident pion bean energies representative of the throe experiments. The AGS experinent would run at $25 \mathrm{GeV}$, the Serpukhov experiment at 50, and this experinent at both 50 and $80 \mathrm{GeV}$. He use the provious equations, $q^{2}=2 m_{e}^{2}-2 m_{e} E_{e}$ and $q_{\max }^{2}=$ $-\frac{4 m_{e} p_{\pi}^{2}}{m_{e}^{2}+m_{\pi}^{2}+2 m_{e}{ }_{n}}$ where $p_{\pi}, E_{\pi}$ refer to the initial pion; $m_{e}$ and $m_{\pi}$ are the cloceron and pion nass; and $\mathrm{E}_{\mathrm{c}}$ is the final state electron energy. 


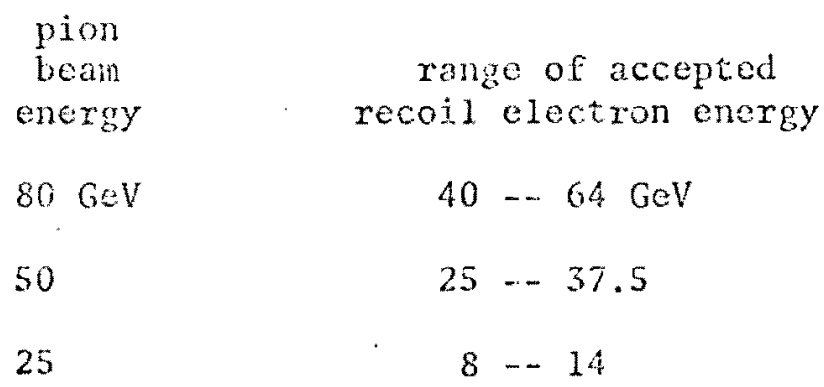

\begin{tabular}{|c|c|c|c|c|}
\hline \multicolumn{5}{|c|}{$\%$ deviation } \\
\hline$\left\langle r_{\pi}\right\rangle=$ & $0.81 f$ & $\left\langle r_{\pi}\right\rangle$ & $=0$ & $.64 f$ \\
\hline $23 \ldots$ & 36 & 14.5 & - & 23 \\
\hline $13.5 \cdots$ & -21.5 & 8.5 & - & 15.5 \\
\hline $4.7-$ & -8.0 & 2.9 & $-\infty$ & 5.2 \\
\hline
\end{tabular}

Three other methols have been used to measure the pion forn factor. Bozklman et al. and Mistretta et al." isolated the one-pion exchango djagram in $\pi^{*}$ electroproduction and measured its contribution as a function of $q^{2}$ to extrect $\left\langle\mu_{\pi}\right\rangle$. They find $\left\langle x_{\pi}\right\rangle=0.8+0.1 f$ but the result is uncortain theorescally becase of the difficulty in estinating the contribution of other toms to the cross section. Block et al. ${ }^{5}$ use $\pi^{t}$ - He elastic scattoring to finl the pion forn factor via an interference effect. They finc $<x_{\pi}><\times 10^{-13} \mathrm{~cm}$. This method also suffers from significant weontainty due to the contribution of terms other than Coulomb scattering. The third nethod is via colliding beans. These elegant experinents measure the form factor in the time-like rogion so that a neasuroment of the formfactor in the speco-like jegion provides an opportunity to test the ability to extrapolate to short distances. At the present time, if the electroproduction expexinents aro correct, this extrapolation fails ${ }^{6}$ as can bo soen in lijg. 1 . We choose 50 and 80 GeV to perform this experinent because

1) The offect in the cross section is larger than at lower cnergies.

2) Backgrounds leading to systenatic errors can be suprossed via longitudina momentum belance at these energies. This might not bo possible at higher encrgies. $\pm 0.1 \%$ resolution in inconing and 


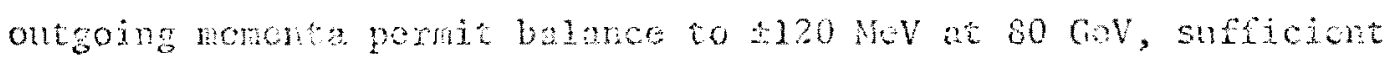
to roject backgrounds in the final state from strong interaction by tio standard deviations.

3) Comting ratos decrease with energy but are stil1 more than adequate.

4) Systomatic effects in efficioncies aro ancrgy indopendent and their effect is less pronomoed char at loner enorgios.

\section{EXPERTMUM, DETALS}

Introduction

A diagran of the exponimental layout is shown in fing. 2. The apparatus

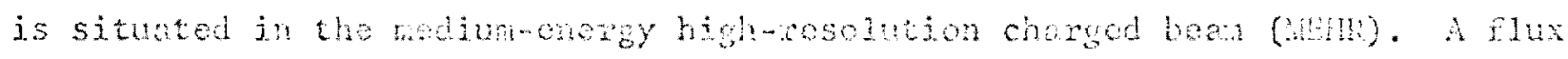
of $3 \times 10^{6}$ chergod pions/ruse is indidont on a som liquid hydrogon tarat.

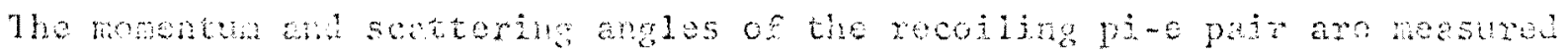

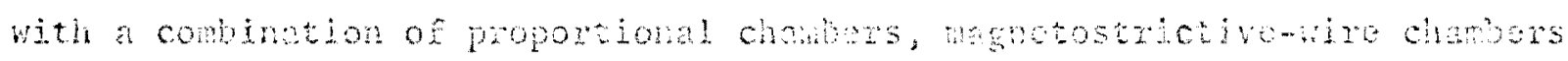

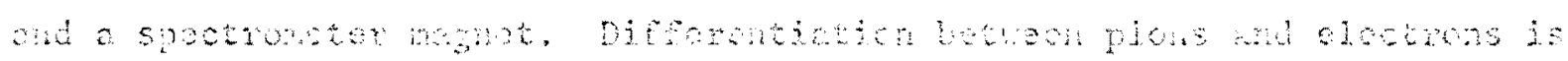

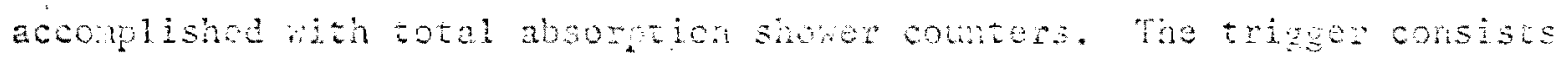

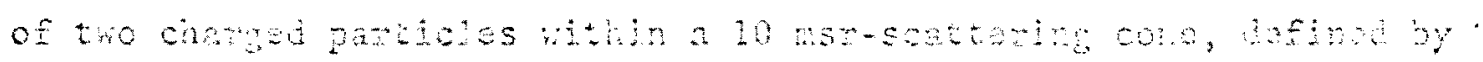

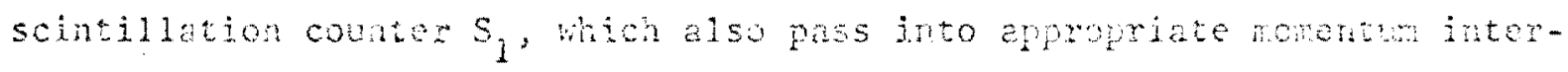
vals defins by scintildation countexs $S_{2}$ and $S_{4}$. The particle momenta accopted by the apharatus at 50 and $80 \mathrm{GeV} / \mathrm{c}$ aro shom belon.
Irojomt Moontun
Pion lango
Llectron Rango
$50 \mathrm{GeV} / \mathrm{c}$
$12.5-25 \mathrm{Cov} / \mathrm{c}$
$25-37,5 \mathrm{Gov} / \mathrm{c}$
$80 \mathrm{GoV} / \mathrm{c}$
$16 \quad-40 \mathrm{Gov} / \mathrm{c}$
$40=64 \quad 6 \in V / c$

Chared particlo bakgroun from the hylogn taret is rojected in thin

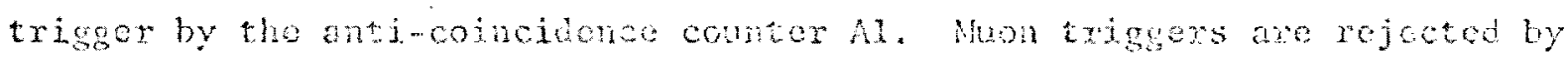

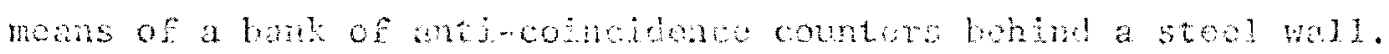


We will rum the experiment with regatively and posteively charged pions at $50 \mathrm{GeV} / \mathrm{c}$ and with negative pions at $80 \mathrm{GeV} / \mathrm{c}$. positive pions will be used to test for charge dopondent systenatic effects, while the $80 \mathrm{GoV} / \mathrm{c}$ data vill dotemine energy dependent systematic efrocts. With an incident $\pi^{-}$beam, a single spectrometex ara behind the magnet is necossury. In Figure 2 , this consists of wire chombers SC 1-A, scintillation counters S2 and St, showex couters S3 and Ss, and the mun telescope. The manet polurity is set appropriately to bend negativoly cherged particles inco this arin. With an incident ${ }^{+}$beam, the nagnet polarity is rovesod such that nogetivoly chargod particlos are bent in

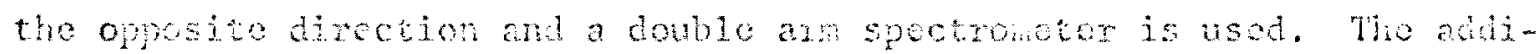
tional am now decots tho recoll electon and consists of wro chamers

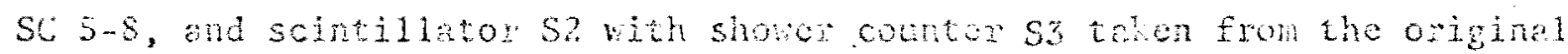

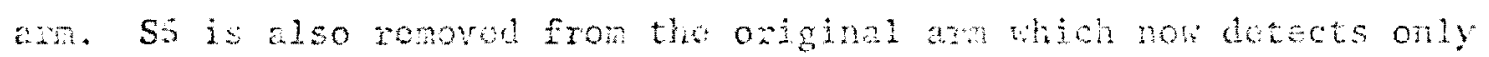
$\pi^{+} \operatorname{anc}^{+} \mu^{+}$.

Resoliting

Adoqute momentwa rosolution is obtancd by sucing the chabers bofore and after the snectroneter nngnet over a 10 motor interval and by requiring the field integral for the spectroneter nagnet to be $100 \mathrm{kgauss-}$ maters. The monntwi resolution is then given amproximately by

$$
\frac{\Delta p}{p}=1.1 \times 10^{-4}\left(.045 p^{2}+31\right)^{1 / 2}
$$

whore $p^{2}$ is in $(G e V / c)^{2}$. 
The romentum dependent toxm is besol upon a 0.5 nra sparl resolution, the nomentum independent tern cones froin mutiple scettering. The terms are, approxinately equal at $25 \mathrm{GeV} / \mathrm{c}$ where the rosolution is $10.1 \%$. Multiple scatcering diminishes in importance at higher energies. At $50 \mathrm{GeV} / \mathrm{c}$ the momentum balance can be done at a precision such that $\Delta \mathrm{E}_{f}= \pm 50 \mathrm{MeV}$.

The horizontal apercure of the magnet should be $48^{\prime \prime}$ in ordex to accept the vide momentun range of the final state. A $10^{\prime \prime}$ gap is adecuate for a $10 \mathrm{~ms}$ accoptance in the vertical dixection. A hodoscopo placed at the monentun slit of the incident pion beam will. serve to define the incident pion energy to $\pm 0.1 \%$ so that at $50 \mathrm{GoV} / \mathrm{C}, \mathrm{ML}_{i}=50 \mathrm{MeV}$. The longitudinal momontum belmoe will be \pm 80 Wov at $50 \mathrm{GoV} / \mathrm{c}$ and $120 \mathrm{NeV}$ at $80 \mathrm{GrV}$.

Evont Rece

Our escimates of runing time are besed on the followirg considerations. The ghobha cross section is given by

$$
\frac{d o}{d E}=\frac{2 n_{0}^{r}{ }_{0}^{2}}{E^{2}}\left(1-\frac{E}{F_{n}}\right) \quad \begin{aligned}
& \text { where } E=\text { encigy of outgoing } \\
& e^{-} \text {and } E_{n} \text { is its reximu } \\
& \text { value }
\end{aligned}
$$

Electrons are accepted between 25 and $37.5 \mathrm{GoV}$ for the 50 GeV case, thus

$$
\begin{aligned}
\sigma & =25.5 \times 10^{-29} \int_{25}^{37.5} \frac{\mathrm{d} \sigma}{\mathrm{dt}} \mathrm{dE} \\
& =0.645 \mu \mathrm{b}
\end{aligned}
$$

For $100 \%$ goometric efficioncy and a $50 \mathrm{~cm}$ hydrogen target, the yield is

$$
\mathrm{Y}=1.4 \times 10^{-6} \text { per incidont pion. }
$$


At $50 \mathrm{GeV}$ we wil run the ben of $3 \times 10^{6}$ negative pions por pulse, the event trigger rato boing

$$
\mathrm{T}_{\mathrm{e}}=1.4 \times 10^{-6} \times 3 \times 10^{6}=4 \mathrm{pex} \text { pusso }
$$

The $7^{-}$flux at 80 Gov will be lower, ve expect only $10^{6}$ per pulse. The $50 \mathrm{GeV} \pi^{+}$bean concains $60^{\circ}$ protons so wo vill limit its intonsity to $10^{6} \pi^{+}$por pulse. Ruming time would be proportioned as follows:

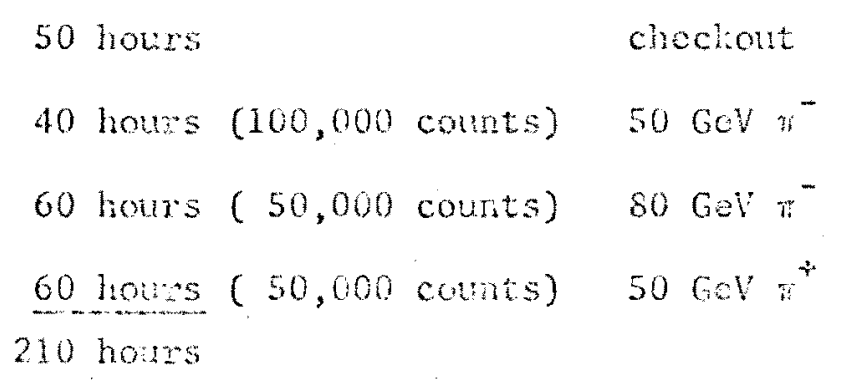

In order to accopt $3 \times 10^{6}$ nogative pions/pulse at $50 \mathrm{Gov} / \mathrm{c}$ we will use proportional chabors to define the trajoctories of the indident pion and the recoiling pite pair. The poprotional chabors uptrest of the hydrogen target wil also be uscd as bom countors. In the rear of the manot, whore bavd lowling con bo avoided and whe an increased ared is involved, magnctostrictivenire chembers vill be used. Backgromis

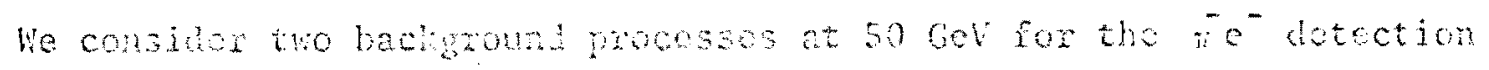
configuretion ony, The tinst is

$$
\begin{aligned}
& \pi^{-}+p+\pi^{-}+p+\pi^{0} \\
& \therefore \rightarrow \gamma+\gamma \\
& \text { L...... } \mathrm{e}^{4} \mathrm{e}^{-}
\end{aligned}
$$


llore a $\gamma$ ray fron the $\pi^{\circ}$ concerts to an $\mathrm{e}^{+} \mathrm{e}^{-}$pair, the $\mathrm{r}^{-}$and $\mathrm{c}^{-}$ simulating a scattering cvent. The yield from this reaction has bocn calculated by the burna group ${ }^{7}$ by as suming that the yide of scondiries from incidont pions is the sane as that from incidont protons. The very small solid angle of the $i-e$ process is of groat importance in rejocting these strong interactions backgrounds. The probability per incident pion that the $\pi^{-}$and $\pi^{\circ}$ be produced in the approprate solid! angle and monentum incervad is

$$
\mathrm{P}=\mathrm{P}_{\pi^{-}} \cdot \mathrm{P}_{\pi^{\circ}}
$$

where $P_{10}$ and $P_{q}-$ are the separate probebilities for the o" and $\pi^{-}$. They find the probibility to bo

$$
\mathrm{p}=10^{-3} \times 10^{-3}=10^{-6} \mathrm{pos} \text { incident pion }
$$

The probability of conversion of a y ray win an $0^{-}$energy in the triggoring range is $10^{-2}$. The ant-coincidones comber aroud the target shoud furber reduce this backgromd at least a facto: of $10^{-1}$ as estimated by a lonte

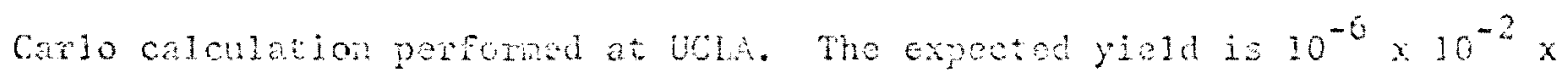
$10^{-1}=10^{-9}$ por incident pion. Coplanarty and oponing anglo cuts roduce this background in analysis by another factor of $10^{-2}$. With an cvent yield of $1.4 \times 10^{-6}$, this background ratio is

$$
B=\frac{10^{-9} \times 10^{-2}}{r}=\frac{10^{-11}}{1.4 \times 10^{-6}}
$$

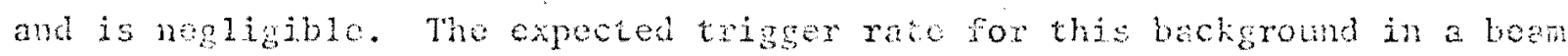
of $3 \times 10^{6}$ pions i.s

$$
\mathrm{T}_{\mathrm{b}}=10^{-9} \times 3 \times 10^{6}=3 \times 10^{-3} \text { per pulso }
$$


The socond bachgound procose that wo hro considored is

$$
\pi^{-*}+p \rightarrow \pi^{-+}+\pi^{-}+\pi^{+}+p
$$

Here one $\pi^{-}$is incorrectly interpreced as an $\mathrm{e}^{-}$. The $\mathrm{T}^{-} \mathrm{Ti}^{-}$yield calculated by the Dubna group into the solid anglo and monentum acceptence is expocted to be

$$
P=3 \times 10^{-4} \text { yer incident pion }
$$

Because of this high yiald we have pewaned a vonte carlo calculation for this reection. The progran yes besed upor:

1) peripheral $\Delta^{+3}$ production,

2) phase spuce for the " "r" pair,

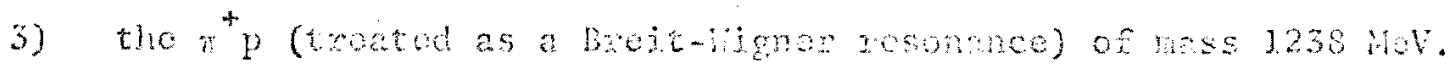

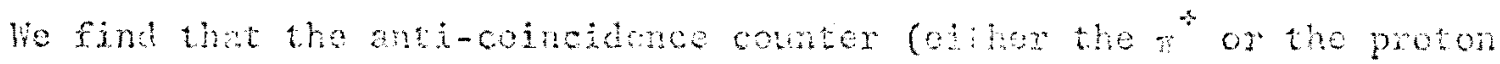
woro requirel to traverse now then $2^{n}$ of hydrogen) anound the target is

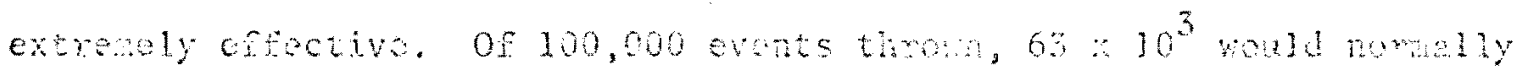
heve trigsand the appratus, hat only 37 suvined the anti roindicace.

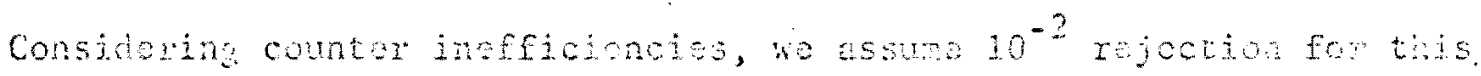

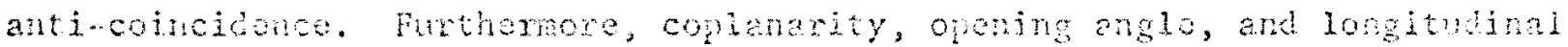
monentua balance cuts roduce these 650 events furthox. Thus only fire candidates are left after andysis. Shover counct identification of tho electron should reduce this by an abitionol facto of $10^{- \text {? }}$. he find for the baelground mato

$$
\begin{aligned}
B & =3 \times 10^{-4} \times \frac{5}{63 \times 10^{3}} \times 10^{-2} \times \frac{1}{Y} \\
& =1.7 \times 10^{.4}
\end{aligned}
$$


and for the trigsex rate (we assum no rojection by the shower countor in the trigger)

$$
\begin{aligned}
\mathrm{T}_{\mathrm{b}} & =3 \times 10^{-4} \times 10^{-2} \times 3 \times 10^{6} \\
& =9 \text { per pulse }
\end{aligned}
$$

We estingta nll other beckgomds to be smal. Proton and kan seatcors comot be conmsed with toe scatering cronts because the kinematios ate complotoly difforont. Electron contonination in the bom con

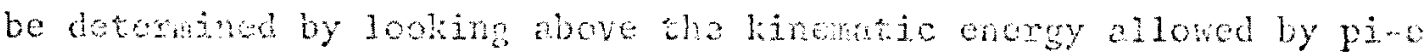

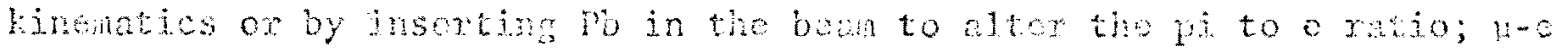

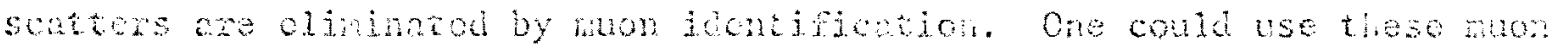

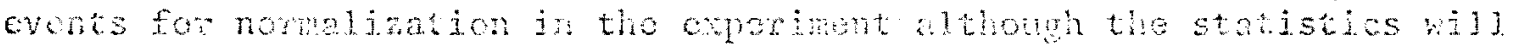
be linited $(\because 2,000$ eventos). Rationive corgentons

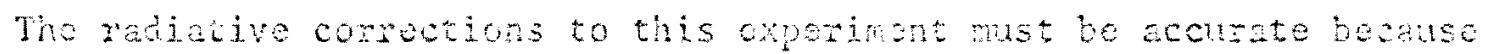

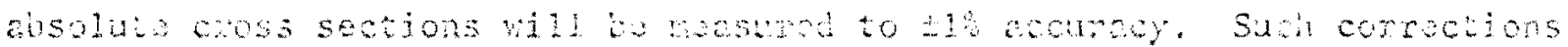

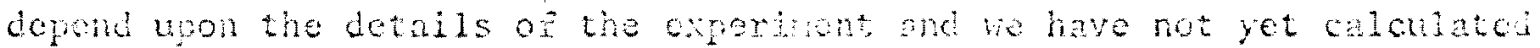
thon precisoly. In prinoiplo, they are, exactly calculable if the cxperinontal rosolution is wold-knom; so tha no fundantal problems are expoted. be

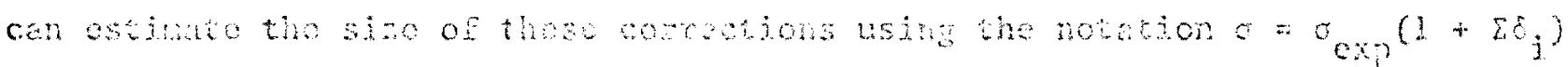
whore the $\hat{o}_{i}$ are rount as followe.

For a 0.28 monontm rosolktion of the ougoing maticle, the bronsstrahlung corroction for $25 \mathrm{~cm}$ of hydrogen is 


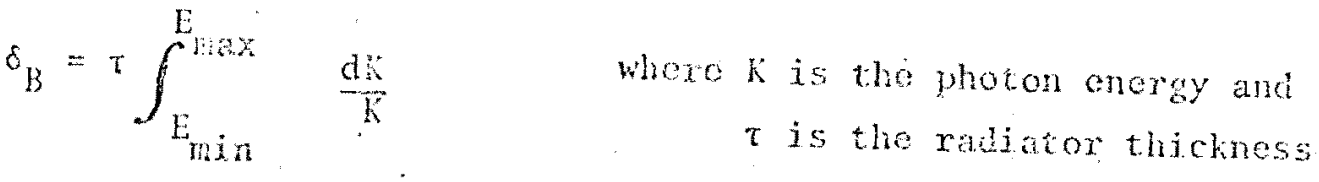

$$
\begin{aligned}
& =0.025 \text { In } \frac{35 \mathrm{GeV}}{35 \mathrm{MgV}}= \\
& =0.0155
\end{aligned}
$$

The lawing los for the particles in the targot is small because the

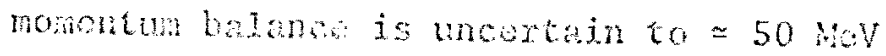

$$
\begin{aligned}
& \delta_{L}=\frac{\xi \theta}{h !} \quad \text { whese } \xi=30^{-2} \\
& \therefore 0.005 \\
& \ell=25 \mathrm{~cm} \\
& \Delta E=50 \%
\end{aligned}
$$

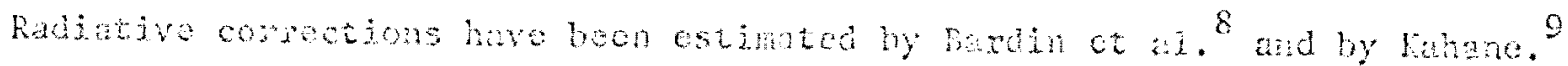

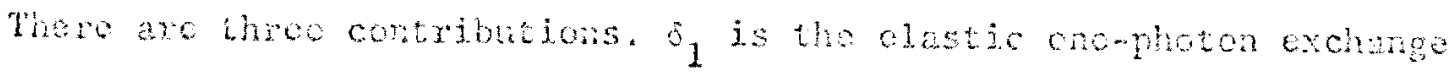
contribution.

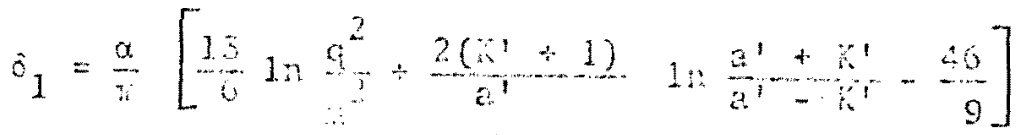

whore

$$
\begin{aligned}
& k^{\prime}=\frac{q^{2}}{2 n^{2}} \\
& a^{\prime}=\left(k^{2}+2 k^{\prime}\right)^{1 / 2}
\end{aligned}
$$

At 50 GeV and nasimn nomontm transon, this tome is

$$
\delta_{1}=-0.55
$$

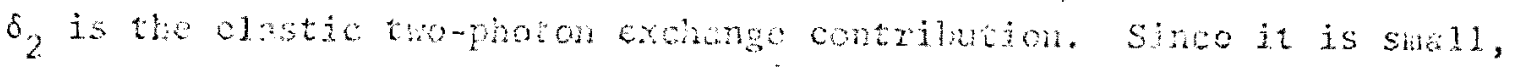
we ignowe its contuntion for this disonsion. 


$$
s_{2}=0
$$

The third contribution $\delta_{3}$ is fron diagrans yith oxtcrul photon Iines. This correction depends on tho experinontal resolution. We approximate this rosult by considoring only thase terms dependent upon fromontum resolution and by ignoxing the angular moisurements. The resulting cxpression is lengthy but gives aproximately

for our cxperincntal conditions.

$$
\delta_{3}=0.15
$$

The total correctron is

$$
\begin{aligned}
& \delta=\delta_{B}+\delta_{L}+\delta_{1}+\delta_{2}+\delta_{3} \\
& \delta=0.255
\end{aligned}
$$

The uncerainty in the correction depuds in pinciple only on the know ledge of our experinment resolution and this will be studiod jn datail in the couse of the experinon.

IV. APARATUS

The najor components of the arparatus shom in Fig. 2 ate as foliove:

1) A liquid-hydrogen targes $50 \mathrm{~cm}$ long.

2) An analyzing nagnet with a fiold intogral of 100 kgauss-metcrs.

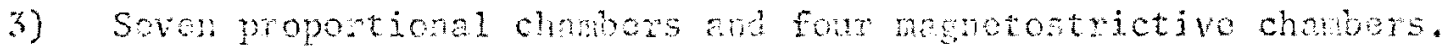

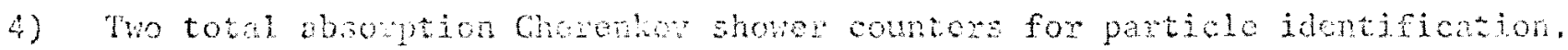

5). A mon lell tor mon rajection.

6) Scintilution counters for teicsoring puroses and for anticoincidence aromet the liguidmydrogon target.

7) A differentin Cherenkon comter for tegging bear pions. 
We will require that NAL supply the analyzing magnet, the liquid hydrogen target, and the differential cherenkov counter. The magnet should be approximately five meters in length with a peak field of $\simeq 20 \mathrm{~kg}$. The dowstrom liniting aperture should be $48^{\prime \prime}$ horizontally by $10^{\prime \prime}$ vextically. It would be acceptable to break the nagnet into two separate magnets. In this case the aperture of the upstream magnet could be reducol to about $8 " \times 24 "$. "The liquid hydxogen target should bo $3 \mathrm{~cm}$ in dianoter and $50 \mathrm{~cm}$ long. It rust have an accurately known donsity and length.

Wo will supply ow ow on-line computation in the form of a HevlettPackad 2116l compun. Howner, we would like to tie this into a larger compater for an additional floating-point facility if one is availaule. The amaratus requires no scoming facilities.

Wo will also require from NAL the fast electronics to form a triggex. UCLA vill supply the romindex of the apparatus including the electronics for the proportional chambers. They will have an active volume of $30 \mathrm{~cm}$ by $30 \mathrm{~cm}$. Since the domstrean chambers are large $(1 \mathrm{~m} \times 2 \mathrm{~m})$, they $\mathrm{il1}$ be "conventional" wire chmbers with magnotostrictive readout. In order to use them effectively the area of the incident pion beam vill be doadened.

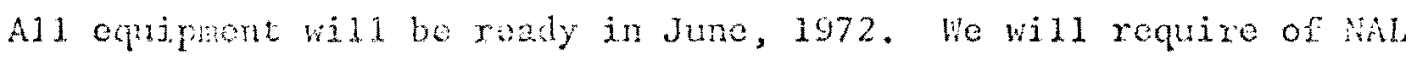
the usual support facjlities involved in the setup and runing of an experiment. 
RERTRHACHS

1. J. J. Sakurai, private commication.

2. D. G. Cassel, "Experimont Moasticent of the Electronagnetic Fom Factor of the Nogative "Moson," fochical Report No. 37 Princeton Univessity, New Jersey, 1965.

3. C. W. Akerloe, W. U. Ash, K. Borkoman, C. A. Lichtonstein, phys. Rev. Loters, 16,147 (1906).

4. C. Mistretre, D. Imxio, J. A. Appol, R. Buinitz, L. Carrol1, M. Goitoin, K. Hanson, and Richow Wison, Piys. Rov. Letrexs, 20, 1523 (1968).

5. M. H. Block, I. Kenyon, J. Koon, K. Koothe, P. Whlhorn, R. Walker, and 11. Hinelor, thys. Bov. 168, 1079 (1968).

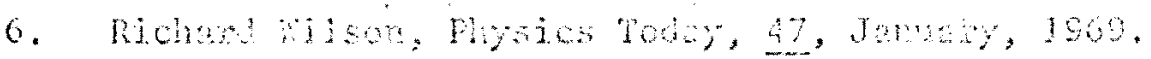

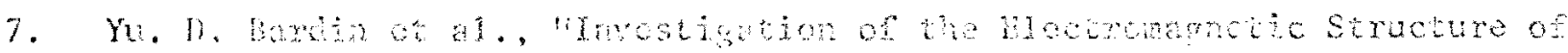
the n neson using the IHEP Accaleraton," (ckperimotol proposal), Whan repert no. El-itos.

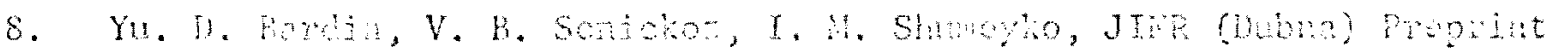

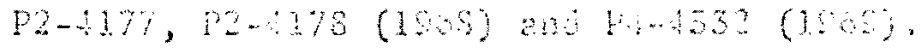

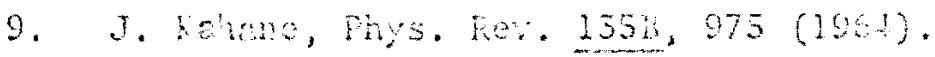






PION FORM FACTOR (squared) in both time-like and space-like regions. Data from four laboratories is compared to the vector-dominance model (black lines; solid

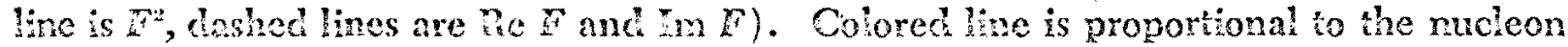
form factors. Vector-clominance model has a single resonance and has small adjustments to satisfy analyticity requirements. 


\section{EXPERIMENTAL LAY-OUT FOR PION-ELECTRON SCATTERING}

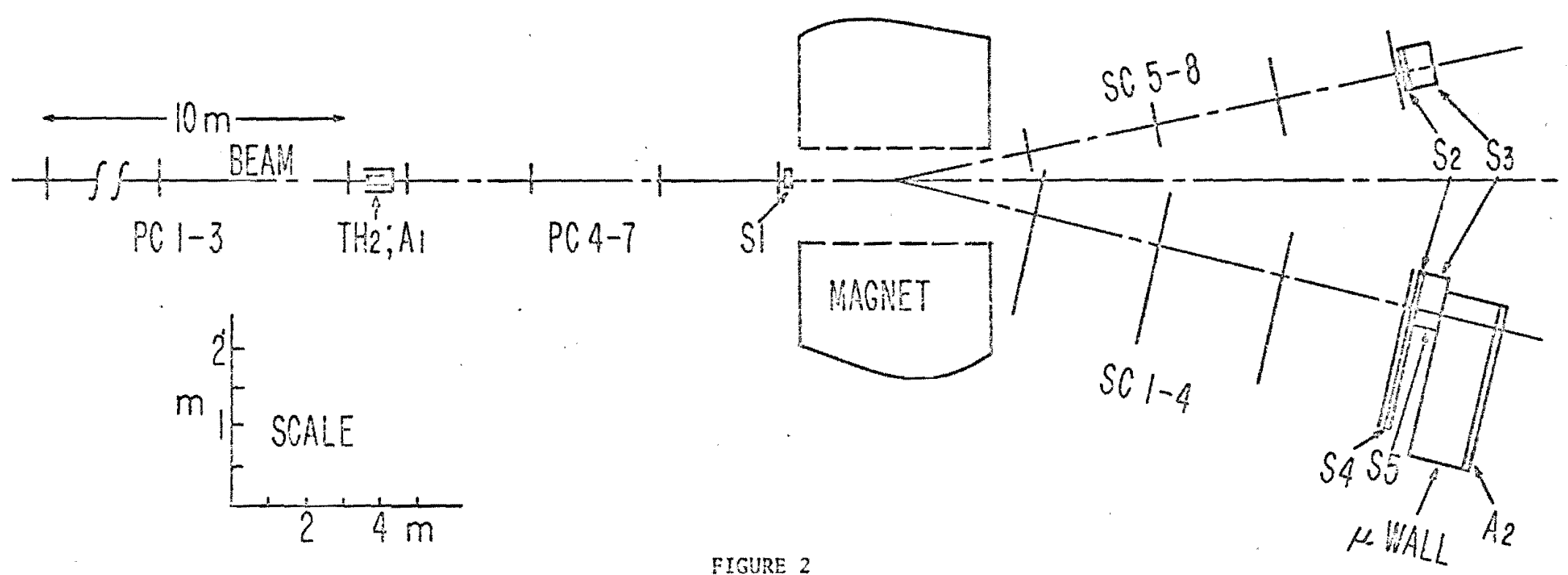

PC 1-7 are proportional chambers; SC $1-8$ are magnetostrictive wire chambers; $\mathrm{TH}_{2}$ is the 1 iquid-hydrogen target; $A_{1}$ is the anti-coincidence counter for the target; $S_{1}$ is a scintillator which defines the acceptance; $S_{2}$ and $S_{4}$ are scintillators which detect the pion and electron; $S_{3}$ and $S_{5}$ are shower counters; $A_{2}$ is an anti-coincidence counter for muon rejection. 